\title{
JEPAPLOK:
}

\section{KOREOGRAFI PENGGAMBARAN HEWAN MITOLOGI JAWA}

\author{
Chorine Nur Shofa \\ Jurusan Tari, Fakultas Seni Pertunjukan Institut Seni Indonesia Yogyakarta \\ Email: chorinens@gmail.com
}

\begin{abstract}
RINGKASAN
Jepaplok merupakan judul dari sebuah karya tari kelompok yang di dalamnya melibatkan sembilan penari perempuan. Kata Jepaplok yaitu berasal dari Njeplak (Manggap) dan Nyaplok (mencaplok). Karya tari ini berawal dari pertunjukan Jaranan di Tulungagung Jawa Timur. Barongan atau biasa disebut Caplokan/Jepaplok adalah penggambaran hewan mitologi berupa ular naga sebagai penguasa hutan yang jahat. Sosok yang dilihat dari segi visualnya menyeramkan dan ganas, serta dari sudut geraknya yang sangat ekspresif. Gerak-gerak dasar yang digunakan antara lain seperti leangleong, ngaplak, ngepruk, sondongan, pattetan, dan sundangan. Karya tari Jepaplok terdiri dari 4 bagian adegan. Pada bagian introduksi dipertunjukkan sosok Barongan dan Jaranan yang berbeda ruang dan kemudian saling menyerang. Bagian 1 berfokus pada gerak Barongan tanpa menggunakan properti topeng. Pada bagian 2 persiapan penyerangan terhadap penari Jaranan, sehingga dalam bagian ini sudah menggunakan properti topeng. Bagian 3 lebih kepada esensi penggunakan topeng dan diolah dengan permainan ritme dan menggunakan komposisi berpasangan. Bagian 4 yaitu akhir dari pertunjukan karya tari Jepaplok yaitu perangan Barongan dan Jaranan. Tetapi pada bagian akhir ini tidak semata-mata saling berhadapan satu dengan yang lain melainkan hanya sebatas permainan per kelompok.
\end{abstract}

Kata kunci : Jepaplok, Barongan dan Jaranan

\begin{abstract}
Jepaplok is the title of a work group in which dance involving nine female dancers. The word Jepaplok is derived from Njeplak (Mangap) and Nyaplok (annexed). This dance originated in the works of interest in dance salon when watching a show used Jaranan (dance horse) in Tulungagung, East Java. The point of view of the Director of the dance stopped when one of the characters enter the staging area performance Barongan. Suspenseful atmosphere emerges when section toward the battle between used Horse and Barongan.

Barongan or commonly called Caplokan/Jepaplok is the depiction of mythological animals in the form of a dragon serpent as ruler of the evil forest. The figure is seen in terms of the Visual sinister and vicious, as well as from the point of a highly expressive movements that inspired the stylist for him to dance in a group dance with paper based on motion and feel the music used Jaranan Sentherewe Tulungagung, East Java. The focus of the implementation work of the dance called Jepaplok is more to perangan and Barongan figures. Basic motion-motion that is used among other things such as leang-leong, ngaplak, ngepruk, sondongan, pattetan and sundangan.

On the work of this Jepaplok dance doesn't bring up the story and consists of four parts of the scene. On the introduction of a dance figure demonstrating Barongan and different spaces used Horse
\end{abstract}


and then each other. Part one that is more focused on motion the Barongan poured into members of the body of a dancer without using the mask property. In part two, namely more to preparation which showed Barongan attacks against dancers used Horse, so in this section are already using property mask. Part three more to the essence of the use of mask and mingled with the game rhythm and composition using paired. Part four, namely the ending of the show dance work Jepaplok, as in general the final part of the art used Horse namely perangan and Barongan used Horse. But in the end it's not solely face each other with one another but rather only as a game between groups.

Key words: Jepaplok, Jaranan and Barongan

\section{PENDAHULUAN}

\section{Jaranan (Tulungagung) atau di} Yogyakarta dikenal dengan sebutan Jathilan adalah salah satu jenis tarian rakyat yang bila ditelusuri latar belakang sejarahnya termasuk tarian tertua di Jawa, khususnya di sekitar Jawa Tengah dan Jawa Timur. Tari yang selalu dilengkapi dengan properti berupa kuda kepang ini lazimnya dipertunjukkan sampai klimaksnya dengan keadaan tidak sadar diri pada salah seorang penarinya. ${ }^{1}$ Sebagian besar dari beberapa kesenian Jaranan yang ada di Jawa sudah mulai mengalami perkembangan yang sudah banyak terkontaminasi dari beberapa aspek.

Pada setiap pertunjukan kesenian Jaranan memiliki beberapa bagian atau struktur dalam bentuk penyajiannya sesuai dengan komunitas dan jenis kesenian Jaranan itu sendiri. Misalkan pada struktur penyajian

${ }^{1}$ Soedarsono, ed. 1976, Mengenal Tari-tarian Rakyat di Daerah Istimewa Yogyakarta, Yogyakarta: Akademi Seni Tari Indonesia Yogyakarta, p. 10.

${ }^{2}$ Eko Wahyuni Rahayu, ed, 2009, Koreografi Etnik Jawa Timur. Surabaya: Dewan Kesenian Jawa
Jaranan Jawa yaitu jejer jaranan, babak berpasangan, babak barongan dan babak celengan. $^{2}$ Banyak masyarakat saat ini lebih menyukai hal yang lebih memiliki daya tarik tinggi atau yang sedang digandrungi. Beberapa bentuk penyajian Jaranan saat ini sudah banyak yang menambahkan unsur dangdut, yang sangat meriah dan para penari tetap menari dengan santai gembira sesuai dengan gerakannya yang dinamis.

Tokoh Jepaplok adalah salah satu tokoh peran utama dalam kesatuan pertunjukan kesenian Jaranan yang lengkap. Jepaplok identik dengan kata njeplak dan kemudian berakhiran plok yaitu nyaplok. ${ }^{3}$ Tokoh tersebut merupakan penggambaran dari hewan mitologi berupa ular naga sebagai penguasa hutan yang kuat dan merupakan simbol tokoh yang jahat. Jepaplok memiliki raut muka yang

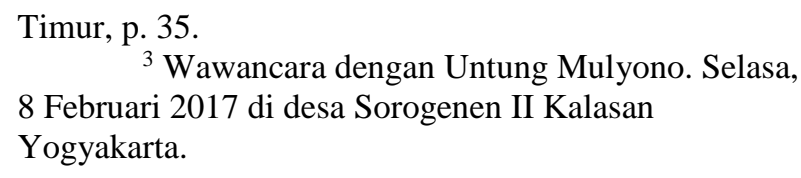


menyeramkan, matanya terbelalak bengis dan buas, hidungnya besar, giginya besar dan bertaring. Masyarakat Jawa Timur khusunya Tulungagung, Kediri dan Trenggalek lebih sering menyebutnya dengan sebutan Barongan.

Pada pertunjukannya para penari memainkan topeng yang sangat besar menyerupai kepala naga. Topeng tersebut dibuat sedemikian rupa sebagai penyimbolan tokoh kejahatan (pengganggu) dan pada topeng tersebut mulutnya dapat dibuka dan ditutup, dengan cara memegang tonjolan kayu yang berada di balik topeng. Terbuka dan tertutupnya topeng tersebut jika dimainkan menimbulkan suara "plok-plok-plok" sehingga banyak masyarakat menyebutnya dengan sebutan "Caplokan". Kepala penari tidak dimasukan ke dalam topeng, melainkan hanya memegang tonjolan kayu dengan kedua belah tangannya, sehingga memudahkan untuk membuka dan menutup mulut topeng tersebut. ${ }^{4}$ Dari gerak tari yang ditampilkan sangat tampak jika Jepaplok tersebut adalah sosok yang adigang, adigung, adiguno yaitu memiliki sifat angkuh, tidak kenal sopan santun dan semaunya sendiri. Hal tersebut sebenarnya merupakan representasi atau simbol dari banyaknya manusia di sekitar kita yang memiliki

${ }^{4}$ Ensiklopedi Seni Musik dan Seni Tari Daerah. 1985, Surabaya: Dinas Pendidikan dan Kebudayaan Daerah Propensi Daerah Tingkat I Jawa Timur, pp. 252-253.

${ }^{5}$ Serba-serbi Jawa Timuran, 2016, Yogyakarta: perwatakan seperti caplokan yang bisa dijadikan cermin agar kita terhindar dari sifatsifat demikian. ${ }^{5}$

Ketertarikan terhadap Jepaplok (Barongan) membangunkan imajinasi serta ideide kreatif yang dikembangkan kembali dalam sebuah sajian yang berbeda. Beberapa hal yang dijadikan sebagai dasar proses penciptaan yaitu berdasarkan ketertarikan penata tari terhadap visual topeng Barongan dan bentuk- bentuk gerak yang disajikan. Dalam konsep penggarapan gerak tarinya lebih menuju kepada bentuk keruangan gerak yang memiliki volume yang besar dan lebar, akan tetapi tidak menutup kemungkinan dalam proses kreatifnya dikembangkan dengan volumenya yang kecil. Penata tari mencoba untuk menuangkan dan mengembangkan gerak-gerak Barongan ke dalam tubuh penari dan menambahkan penekanan-penekanan pada gerak perkelahian atau rampogan ke dalam sebuah koreografi kelompok. Penggarapan karya tari dengan judul Jepaplok disajikan secara representasional yaitu dengan menyampaikan bentuk-bentuk gerak Barongan yang sebenarnya. Gerak leangleong ngalap mongso, ngaplak, dan ngepruk adalah beberapa nama gerak yang sering dilakukan oleh penari Barongan. Selanjutnya

Histokultural. Surabaya: Pena Jawa Timuran, p.5. 
gerak tersebut dikembangkan untuk memenuhi beberapa aspek-aspek dalam koreografi. Struktur penyajiannya dibagi ke dalam empat adegan dengan jumlah penari 9 orang penari perempuan. Karena kesenian ini berasal dari Tulungagung Jawa Timur maka penata tari tetap memunculkan unsur gerak yang berpijak pada gerak-gerak Tulungagungan sebagai salah satu gerak penghubung antara motif satu dengan motif lainnya, seperti gerak sirig, sundangan, dan patte.

\section{PEMBAHASAN}

\section{A. Kerangka Dasar Pemikiran}

Jepaplok merupakan judul dari karya tari yang diciptakan berlandaskan ide yang sebelumnya muncul dari rangsang visual setelah menyaksikan dan mengamati beberapa pertunjukan kesenian Jaranan yang terdapat di Tulungagung.

Penggambaran Barongan tersebut divisualisasikan dengan menggunakan topeng berbentuk kepala ular naga yang dalam masyarakat Tulungagung disebut dengan Barongan. Tokoh ini merupakan simbol tokoh yang jahat, sesuai dengan bentuk visual topeng Barongan, yang memiliki bentuk yang menyeramkan dengan taring yang panjang, matanya terbelalak lebar dan apabila topeng tersebut dimainkan sehingga terbukanya mulut poteng seakan-akan ingin melahap apa saja yang berada di sekitarnya. Gerak-gerak yang ditampilkan sangat atraktif dan ekspresif sehingga menimbulkan kesan keras dan kuat.

Barongan biasanya ditarikan oleh penari laki-laki, karena harus menopang berat topeng yang sangat besar. Untuk karya ini, tokoh ini ditarikan oleh penari permpuan sehingga memunculkan sebuah tampilan baru. Kaum perempuan dapat melakukan apa saja seperti halnya apa yang dilakukan pria. Walaupun pada hakikatnya kaum wanita tidak diwajibkan untuk melakukan sebuah pekerjaan yang merupakan tanggung jawab dari kaum pria. Namun sebagai bentuk emansipasi, kekuatan tidak hanya identik dengan laki- laki, akan tetapi seorang perempuan pun dapat melakukan sesuatu hal yang berat dengan memaksimalkan kekuatannya.

Gerak leang-leong ngalap mongso, ngaplak, dan ngepruk adalah beberapa gerak yang sering digunakan ketika menarikan topeng Barongan. Gerak meliuk tetap dipakai karena Barongan merupakan visualisasi ular naga. Gerak yang ditampilkan akan disesuikan dengan kebutuhan penggarapan karya tari, yang tetap berpijak pada kesenian rakyat di Tulungagung yaitu Jaranan Sentherewe. Sehingga penggarapan gerak pada karya tari ini tetap berorientasi pada aksen-aksen gerak Jaranan seperti kuda-kuda pada kaki dan solah kaki. 


\section{B. Konsep Dasar Tari}

\section{Rangsang Tari}

Rangsang visual merupakan rangsang awal dalam proses penggarapan karya tari Jepaplok. Rangsang tersebut didapat ketika menyaksikan dan mengamati kesenian Jaranan di kabupaten Tulungagung. Pandangan penata tari terhenti pada salah satu tokoh dalam kesenian Jaranan tersebut. Tokoh tersebut memiliki raut muka yang menyeramkan dengan gigi taring yang panjang dan mulutnya terbuka lebar seakanakan ingin memangsa semua yang berada disekitarnya. Ketika mengamati kembali dengan seksama, penata tari tertarik pada gerak-gerak yang dilakukan oleh penari Barongan. Gerak-gerak tersebut sangat atraktif dan ekspresif, sehingga topeng tersebut benar- benar terlihat hidup ketika dimainkan. Rangsang visual inilah yang mengawali keinginan penata tari untuk mengembangkan gerak-gerak Barongan ke dalam penggarapan koreografi kelompok.

\section{Tema Tari}

Tema yang diangkat dalam
penggarapan karya tari ini adalah
pengganggu. Hal ini disesuaikan dengan
beberapa sumber yang menyatakan bahwa
Barongan merupakan simbol kejahatan dan

${ }^{6}$ Direktorat Jendral Kebudayaan Departemen Pendidikan dan Kebudayaan Jakarta, 1978/1979. Reog di Jawa Timur. Jakarta: Proyek Sasana Budaya selalu menghalau siapa saja yang melewati kekuasaannya serta dalam pertunjukan Jaranan merupakan musuh atau malapetaka bagi manusia yang harus disingkirkan. Penggarapan karya tari dengan tema penggaggu disesuaikan dengan bentuk penyajian Jaranan yang memiliki adegan (rampogan) yaitu sebuah perkelahian yang melibatkan prajurit berkuda dan Barongan. Rampogan dengan arti yang lainnya yaitu sebuah pertunjukan berburu harimau; bertarung dengan harimau. ${ }^{6}$

\section{Judul}

Judul dalam karya tari ini adalah Jepaplok. Jepaplok merupakan sebutan untuk tokoh ular naga dalam kesenian Jaranan. Kata Jepaplok memiliki dua unsur arti yaitu dari kata njeplak (mangap) yang identik dengan mulut, kemudian plok berasal dari nyaplok (menyaplok), sehingga dapat disimpulkan bahwa Jepaplok dalam bahasa Indonesia berarti membuka dan menutupnya mulut.

\section{Bentuk dan Cara Ungkap}

Karya tari Jepaplok adalah koreografi kelompok dengan 9 orang penari perempuan. Karya tari ini lebih menekankan pada bentuk dramatik. Bentuk geraknya memiliki kesan lebar, kuat, dan gesit. Beberapa bentuk gerak

Direktorat Jendral Kebudayaan Departemen Pendidikan dan Kebudayaan, p. 164. 
leang-leong ngalap mongso, ngaplak, ngepruk pada penari Barongan akan diolah kembali agar memunculkan suatu gerak yang baru dengan suasana yang diinginkan dan disesuaikan dengan kebutuhan penggarapan tanpa menghilangkan unsur tradisinya. Dramatik yang dihadirkan seperti; suasana menegangkan ketika memasuki adegan peperangan Barongan dan Jaranan serta didukung musik tardisi kerakyatan yang kental.

\section{Konsep Garap Tari}

\section{Gerak Tari}

Kesenian Jaranan merupakan kesenian rakyat yang banyak menggunakan aksi spontanitas pada geraknya. Beberapa gerak yang dikemas dan dikembangkan antara lain gerak pada Barongan yaitu leang-leong ngalap mongso, ngaplak, dan ngepruk. Kekuatan kaki kuda-kuda yang merupakan dasar bentuk gerak Jawa Timur, tetap dipertahankan yang bersumber pada kesenian Jaranan Sentherewe. Melalui hasil gerak-gerak tersebut memunculkan imajinasi gerak tepuk pada kedua tangan yang disatukan, sehingga menimbulkan suara "plok" dan dengan volume gerak yang lebar.

\section{Penari}

Karya tari Jepaplok ditarikan oleh 9 orang penari perempuan. Dalam kesenian Jaranan yang sesungguhnya penari Barongan diperankan oleh seorang laki-laki karena geraknya menggunakan topeng yang besar dan berat sehingga membutuhkan tenaga ekstra untuk melakukannya. Pada era yang telah modern dan merupakan era perubahan, kesempatan kali ini penata tari beremansipasi terhadap kaum perempuan dengan menggunakan penari berjenis kelamin perempuan sehingga dapat memunculkan sebuah tampilan baru. Pemilihan sembilan penari disesuaikan dengan kebutuhan untuk pembagian sebuah komposisi koreografi seperti halnya pada adegan satu hanya menggunakan dua penari, adegan dua dan tiga menggunakan delapan penari dan adegan terakhir menggunakan sembilan penari (lima penari Barongan, empat penari Jaranan). Pada adegan perangan hanya menggunakan delapan penari untuk memenuhi bentuk pola-pola komposisi berpasangan. Berpasangan dalam hal ini dapat digambarkan juga pada aspek kehidupan, di mana manusia memiliki sifat baik dan buruk serta manusia merupakan mahluk sosial yang tidak dapat hidup tanpa bantuan makhluk yang lainya.

\section{Iringan Tari}

Bentuk musik yang digunakan tidak terlepas dari musik tradisi Jawa Timur khusunya nuansa musik Jaranan Sentherewe. Dalam pertunjukan kesenian Jaranan pada umumnya menggunakan live music terdiri dari 
kempul nada 6 , pencon bonang nada $2+6$, kendhang (kendhang batangan dan kendhang bem/besar), Gong Ageng, Gong Suwuk dan slompret. $^{7}$

Pada proses penggarapan musik karya tari Jepaplok menggunakan dua jenis alat musik yaitu berasal dari instrumen musik komputer dan live music yaitu bonang barung, kempul nada $6+5+1$, gong ageng, gong suwuk nada 2 , kendhang bem, kendhang batangan, bedug, simbal dan slompret. Penambahan aspek pendukung yaitu alat musik komputer dapat membantu dalam pembentukan suasana. Karakter musik yang diinginkan yaitu berpijak pada karakter musik Jaranan Sentherewe yang diolah kembali dan disesuaikan dengan penggarapan karya tari. Terdapat penambahan vokal yang diikutsertakan dalam penggarapan musik dalam karya tari Jepaplok agar dapat memberikan variasi dan pembentukan dinamika.

\section{Rias Busana Tari}

Rias dan busana merupakan suatu kesatuan yang utuh dalam diri penari pada saat di atas panggung pementasan. Kaitannya dengan pementasan, dua hal tersebut dapat

\footnotetext{
${ }^{7}$ Wawancara dengan Untung Mulyono. Selasa, 24 Maret 2017 di Gedung Perkuliahan Sendratasik Institut Seni Indonesia Yogyakarta.

8 Budiono Heru Satoto, 2000,
}

dijadikan sebagai uangkapan rekayasa untuk memenuhi kebutuhan dalam penggarapan karya tari, sehingga apa yang menjadi konsep garapan dapat dituangkan pada rias dan busana. Rias yang akan digunakan yaitu rias korektif dengan penajaman garis pada mata dan penajaman pada countour wajah. Busana atau kostum yang digunakan yaitu terbuat dari bahan yang elastis, sehingga dapat dengan mudah menempel pada tubuh dan bahan sehingga memudahkan untuk bergerak. Busana memadukan warna-warna seperti hitam, merah, kuning dan putih. Warna hitam melambangkan sifat perwira satria, dan suka membela kebenaran. Warna putih melambangkan sifat suci lagi luhur. Warna merah melambangkan angkara murka, pemarah dan berani berbuat apa saja. Sedangkan warna kuning melambangkan kemuliaan, kejujuran dan bertanggung jawab. ${ }^{8}$

\section{Tata Cahaya}

Tata cahaya sangat penting peranannya dalam seni pertunjukan, kehadiran tata cahaya harus mampu menciptakan suatu nuansa luar biasa, serta mampu membentot perhatian penonton terhadap tontonannya. ${ }^{9}$ Penggunaan cahaya dalam pementasan disesuaikan dengan karya yang ditampilkan, seperti halnya dalam

Simbolisme dalam Budaya Jawa. Yogyakarta: Hanindita Graha Widia, p. 86

${ }^{9}$ Hendro Martono, 2010, Mengenal Tata Cahaya Seni Pertunjukan. Yogyakarta: Multi Grafindo, p. 12. 
memperkuat suasana dengan menggunakan pencahayaan mood yaitu di dalamnya terdapat warna dingin (cool colors) dan warna hangat (warm colors). Pada karya tari Jepaplok menghadirkan beberapa suasana yang hangat (menegangkan) dengan beberapa pilihan warna seperti merah, kuning, dan oranye.

\section{Pemanggungan}

\section{a. Ruang Pentas}

Karya tari Jepaplok dipentaskan di proscenium stage. Pemilihan ruang pentas tersebut dikarenakan dalam karya tari ini banyak menggunakan exit-entrance penari, satu sudut pandang, dan setting panggung yang hanya bisa dilakukan di proscenium stage.

b. Lokasi Pementasan

Lokasi yang dipilih untuk pementasan karya tari Jepaplok adalah Auditorium Jurusan Tari, Institut Seni Indonesia Yogyakarta. Hal ini dasarkan atas tujuan pementasan yaitu sebagai pertunjukan karya Tugas Akhir.

\section{Tata Rupa Pentas}

a. Properti

Karya tari Jepaplok menggunakan properti khusus yaitu berupa topeng Barongan, Jaranan, dan Pecut. Pembuatan topeng Barongan disesuaikan dengan kebutuhan pementasan, yaitu mulai dari pemilihan warna dan beberapa aksen yang digunakan sebagai aksesoris atau pemanis.
Pemilihan bahan dasar juga menjadi pertimbangan, yaitu menggunakan bahan baku kayu yang sekiranya tidak terlu berat dan pada hiasan jamang terbuat dari bahan baku Busa Hati (Eva Sponge Sheet). Properti Jaranan merupakan kuda-kudaan yang terbuat dari ayaman bambu yang didesain sedemikian rupa agar mempermudah pemakaian yaitu dengan penambahan tali yang dikalungkan pada leher. Properti pecut yang digunakan yaitu terbuat dari bahan dasar njalin dengan pegangan yang bermotif dengan sulaman benang yang kuat. Apabila digerakkan properti ini sangat lentur dan menimbulkan suara yang nyaring.

b. Setting Panggung

Setting dalam karya tari Jepaplok menggunakan level berukuran $2 \mathrm{x} 1$ berjumlah 1 buah, 1x1 berjumlah 2 buah. Serta penggunakan asap yaitu berasal dari pembakaran arang di atas anglo. Penggunakan setting ini digunakan pada bagian akhir pementasan pada bagian ending.

\section{Realisasi Karya}

\section{Urutan Adegan}

Karya tari Jepaplok dalam tahapan realisasi proses dan hasil penciptaan karya, dibagi dengan beberapa adegan atau segmen, yaitu: 
a. Introduksi

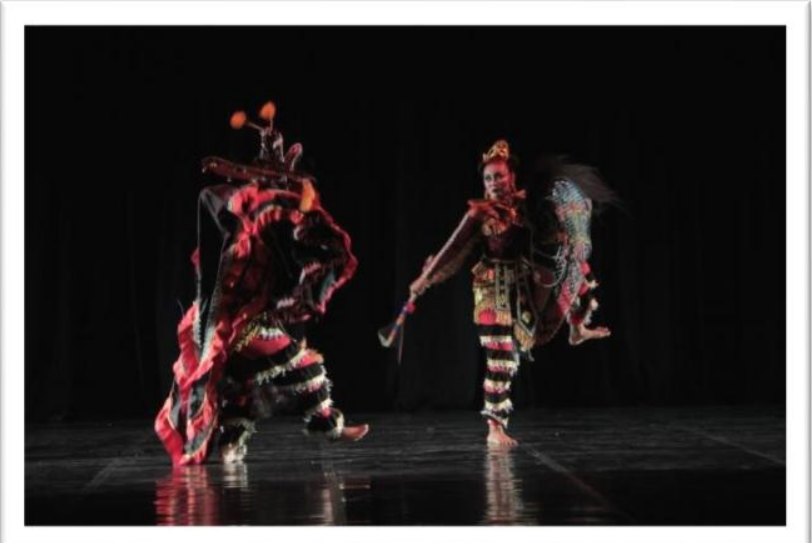

Gambar 1. Gerak perangan antara Barongan dan Jaranan. (Dok. Ari, 2017, Yogyakarta)

Pada bagian awal introduksi ditampilkan dua karakter yang merupakan tokoh dalam sebuah serangkaian kesenian Jaranan lengkap. 1 Barongan masuk dari sisi down right stage, dengan suasana musik menggeru. Kemudian dari sisi up left stage 1 jaranan masuk dengan suasana musik yang menunjukkan semangat yang menggebu-gebu. Iringan musik pada adegan ini yaitu menggunakan live music yang berpijak pada nuansa musik Jaranan Sentherewe.

\section{b. Adegan 1}

Pada bagian 1 diawali dengan menggetarnya tirai samping kanan dan kiri (wings) lalu masuk 7 penari Barongan. Pada adegan ini penari tanpa menggunakan properti yaitu lebih berfokus pada pengaplikasian gerak Barongan ke anggota tubuh penari (seperti halnya njeplak/mangap yang pada bagian ini divisualkan dengan tepukan kedua tangan dan ekspresi wajah). Lainnya seperti ngepruk dengan menepukkan telapak tangan ke bagian paha atas dengan bergantian. Nyaplok dengan dua tangan di atas kepala lalu dihentakkan secara tiba-tiba.

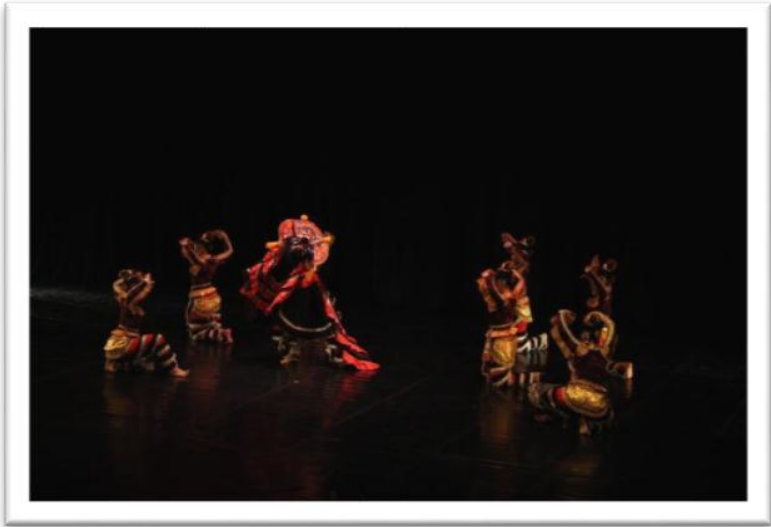

Gambar 2. Gerakan setelah para penari menggetarkan sidewings kanan dan kiri. (Dok. Ari,2017, Yogyakarta)

\section{c. Adegan 2}

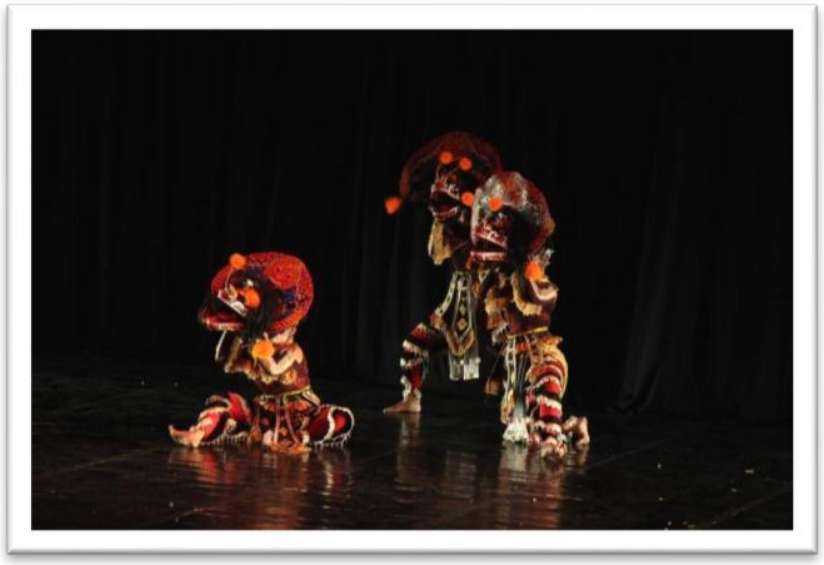

Gambar 3. Bagian II dengan tiga penari berada pada up center dengan menggunakan properti topeng Barongan.

Pada adegan 2 gerak-gerak Barongan dengan menggunakan Topeng yang 
menunjukkan persiapan menghadapi lawan. Diawali dengan masuknya tiga penari dari $u p$ center stage, dengan menggetarkan topeng kemudian menggulung maju ke dead center. Disusul dengan suara-suara pecut yang memekik menandakan akan segera menghadapi lawan dan penari Jaranan memasuki area pementasan dari side wings kanan dan kiri.

\section{d. Adegan 3}

Pada bagian ke tiga diawali dengan masuknya seluruh penari Barongan dengan propertinya yaitu topeng Barongan sebanyak delapan penari. Adegan ketiga lebih berfokus pada penggolahan topeng barongan dengan menggunakan permainan ritme yang diaplikasikan pada membuka dan menutupnya mulut topeng sehingga dapat menambah kesan ekspresif dan dinamis. Selain itu komposisi berpasangan seperti halnya pada komposisi dalam kesenian Jaranan yaitu posisi Enjer dan Prapatan di pergunakan dalam adegan ini.

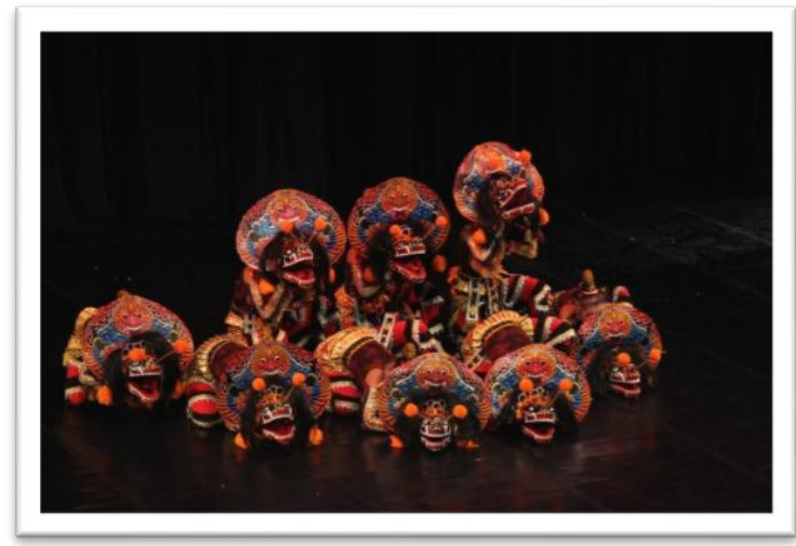

Gambar 4. Komposisi rampak nyaplok. Dok. Aldi, 2017, Yogyakarta) e. Adegan 4

Pada bagian ini penata tari ingin menunjukkan kembali konflik yang terjadi sebelumnya, dengan pembagian empat penari Jaranan dan lima penari Barongan. Diawali dengan ke luarnya empat penari Lia, Hana, Risa, Yussi, kemudian selang beberapa menit terdengar ater-ater dari kendhang menandakan akan segera muncul Jaranan. Barongan sebagai penghalau berusaha menghalau segala sesuatu yang ada. Hingga mulai memasuki akhir pertunjukan peperangan kembali terlihat akan tetapi pada bagian ini menggunakan peperangan yang tidak secara langsung saling berhadapan, melainkan dengan permainan per kelompok.

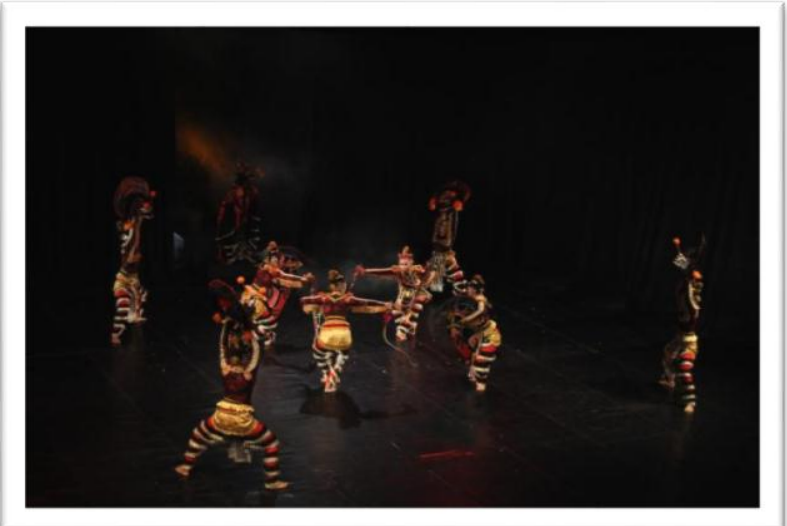

Gambar 5. Komposisi ending sebelum melakukan perangan antara Barongan dan Jaranan. (Dok. Aldi, 2017, Yogyakarta) 


\section{Realisasi Musik Tari}

Iringan musik yang digunakan dalam karya tari Jepaplok adalah berpijak pada jenis musik tradisi Jaranan Sentherewe dan digabungkan dengan alat musik komputer. Instrumen yang gunakan secara langsung yaitu Gong Ageng, Kendhang Bem, Kendhang Batangan(ciblon), Bonang Penembung, Bonang Barung, Selompret, Kenong nada 2-6, dan Kempul nada 2. Terdapat penambahan Bedug, Simbal, dan Rebana yang merupakan instrumen di luar rangkaian instrumen musik Jaranan, penambahan alat musik didasarkan atas proses pengembangan dari penggarapan musik yang bernuansa Jaranan. Di luar hal tersebut ditambahakan sebuah instrumen atau alat musik komputer, di mana kedua poin tersebut akan dikolaborasikan menjadi satu sehingga dapat memunculkan suatu warna musik yang berbeda.

\section{Realisasi Rias dan Busana}

Pemilihan rias wajah yang digunakan tidak terlepas dari rias untuk sebuah pementasan. Rias wajah korektif, ditambah dengan penegasan-penegasan garis mata dan penajaman warna pada eyeshadow, agar memunculkan karakter yang tegas dan garang disesuaikan dengan konsep penggarapan. Pemilihan busana yang digunakan adalah memilih bahan-bahan yang enak digunakan untuk bergerak, bahan tersebut bersifat lentur sehingga dapat melekat dengan badan. Penambahan beberapa bahan yang dapat menimbulkan efek atau memberi kesan tertinggal ketika melakukan gerak tangan (ngaplak). Pada bagian penari Jaranan penata tari menambahkan kace.

\section{Realisasi Tata Cahaya}

Tata cahaya dalam sebuah pertunjukan merupakan sarana pendukung untuk membentuk suatu suasana yang diinginkan. Penata cahaya adalah cak Eko. Dijelaskan kepada penata cahaya mengenai konsep yang dibawakan dalam karya tugas akhir ini agar apa yang menjadi keinginan penata tari dapat terealisasikan dengan penguatan beberapa tata cahaya yang digunakan. Penggunaan cahaya dalam pementasan disesuaikan dengan karya yang ditampilkan, seperti halnya dalam memperkuat suasana dengan menggunakan pencahayaan mood yaitu didalamnya terdapat warna dingin (cool colors) dan warna hangat (warm colors). Pada karya tari Jepaplok menghadirkan beberapa suasana yang hangat (menegangkan) dengan beberapa pilihan warna seperti merah, kuning dan oranye.

\section{PENUTUP}

Ketertarikan pada kesenian Jaranan menjadi awal dasar terciptanya karya tari 
Jepaplok. Dalam penggarapannya tidak memiliki alur cerita, akan tetapi menggambil beberapa poin dari berbagai unsur di dalam kesenian Jaranan. Salah satunya yaitu tokoh yang berperan penting dalam kesenian tersebut yaitu Jepaplok/Caplokan. Tokoh ini di masyarakat Tulungagung, Kediri dan Trenggalek disebut dengan Barongan. Pada pertunjukannya penari menggunakan topeng yang sangat besar, menyerupai kepala naga. Barongan yang merupakan bentuk visualisasi dari ular naga raksasa memiliki raut muka yang menyeramkan, ganas, mulutnya dapat membuka lebar seolah-olah ingin memangsa segala sesuatu yang berada di sekitarnya. Selain dilihat dari bentuk visual topengnya, bentuk gerak yang tercipta ketika menggunakan topeng Barongan sangat ekspresif dan menarik. Beberapa gerak seperti leang-leong, ngaplak, dan ngepruk merupakan gerak yang sering dilakukan oleh pemain Barongan. Pola gerak tetap berpijak pada kesenian Jaranan Sentherewe Tulungagung Jawa Timur.

\section{DAFTAR SUMBER ACUAN}

A. Sumber Tertulis

Barthes, Roland. 1983. Mythologes. Hill and Wang, New York. Terjemahan dari Nurhadi, A. Sihabul Millah. Mitologi. 2015. Yogyakarta: Kreasi Wacana.

Dana, I Wayan. 2011. Peruman Barong di Pura Puncak Padang Dawa, Baturiti
Tabanan: Prespeksi Kajian Budaya. Yogyakarta: BP.ISI Yogyakarta.

Dinas Pendidikan dan Kebudayaan Daerah Provinsi Daerah Tingkat I Jawa Timur. 1996/1997. Ensiklopedi Seni Musik dan Seni Tari Daerah, Laporan Penelitian dan Pengamatan Kebudayaan Derah Jawa Timur. Surabaya: Dinas Pendidikan dan Kebudayaan Provinsi Daerah Tingkat I Jawa Timur.

Direktorat Jendral Kebudayaan Departemen Pendidikan dan Kebudayaan Jakarta. 1978/1979. Reog di Jawa Timur. Jakarta: Proyek Sasana Budaya Direktorat Jendral Kebudayaan Departemen Pendidikan dan Kebudayaan.

Djatmiko, Gandung. 1987. "Tinjauan Koreografis Jaranan Sentherewe Kediri”, Skripsi Strata 1, Jurusan Seni Tari, Fakultas Kesenian, Institut Seni Indonesia Yogyakarta. Yogyakarta.

Ellfeldt, Lois. 1967. A Primer For Choreographer. Laguna Beach, California. Terjemahan dari oleh Sal Murgiyanto. 1977. Pedoman Dasar Penata Tari. Jakarta: Lembaga Pendidikan Kesenian Jakarta.

Gustini N, Heny., Alfan, Muhammad. 2013. Studi Budaya di Indonesia. Bandung: CV PUSTAKA SETIA.

Hadi, Y. Sumandiyo. 2003. Aspekaspek Dasar Koreografi Kelompok. Yogyakarta: ELKAPHI.

Hadi, Y. Sumandiyo. 2011. Koreografi: Bentuk-Teknik-Isi. Yogyakarta: Multi Grafindo.

Hawkins, Alma M. 1988. Creating Through Dance. New Jersey: Princeton Book 
Company. Terjemahan dari oleh Y. Sumandiyo Hadi. 1990. Menata Lewat Tari. Yogyakarta: Manthili.

Herusantoto, Budiono. 2000. Simbolisme Dalam Budaya Jawa. Yogyakarta: Hanindita Graha Widia.

Hidajat, Robby. 2011. Koreografi \& Kreativitas, Pengetahuan dan Petunjuk Praktikum Koreografi. Yogyakarta: Kendil Media Pustaka Seni Indonesia.

Kayam, Umar. 1981. Seni Tradisi, Masyarakat. Jakarta: Sinar Harapan.

Martono, Hendro. 2010. Mengenal Tata

Cahaya Seni Pertunjukan.

Yogyakarta: Cipta Media.

Martono, Hendro. 2012.

Panggung Pertunjukan dan

Berkesenian.

Yogyakarta: Cipta Media.

Martono, Hendro. 2014. Koreografi Lingkungan Revitalisasi Gaya Pemanggungan dan Gaya Penciptaan Seniman Nusantara. Yogyakarta: Cipta Media.

Meri, La. 1976. Dance Composition: The Basic. Terjemahan dari Soedarsono.1965. Elements Komposisi Tari : Elemenelemen Dasar. Yogyakarta: Akademi Seni Tari Indonesia.

Smith, Jacqueline. 1985. Dance Composition" a Practical guide for teachers. London: A \& Black. Terjemahan dari Ben Suharto,S.S.T. Komposisi Tari Sebuah Petunjuk Praktis Bagi Guru. Yogyakarta: Ikalasti.

Soedarsono R.M., Narawati Tati. 2014.
Dramatari di Indonesia, Kontinuitas dan Perubahan. Yogyakarta: Gajah Mada University Press.

Subagyo, Welas. 1992. "Barongan". Skripsi Strata 1, Jurusan Seni Tari, Fakultas Kesenian, Institut Seni Indonesia Yogyakarta.

Surur, Misbahus. 2013. Turonggo

Yakso Berjuang Untuk Sebuah

Eksistensi.

Trenggalek: Republik Indonesia.

Van Groenendael, Victoria M. Clara. 2008. Jaranan The Horse Dance and Trance in East Java. Leiden: Koninklijkn Institut voor Taal-,Land-en Volkenkunde (KITLV).

Widaryanto, F.X. 2009. Koreografi. Bandung: Jurusan Tari STSI Bandung.

B. Sumber Lisan

Nama : Untung Muljono Alamat : Sorogenen II

RT02,Kalasan,Sleman,Yogyakarta 55571

Umur :59 tahun

Pekerjaan : PNS

Jabatan : Pendiri dan

Penasehat Jaranan Senterewe Turonggo

Wijoyo

Nama

: Bimo Wijayanto

Alamat

: Tulungagung

Umur

: 47 tahun

Pekerjaan

: PNS

Jabatan

: Koreografer

Nama

: Endin Didik Handoko

Alamat

: Sendang

Umur : :45 tahun

Pekerjaan : Seniman

Jabatan : Pemilik Rumah

Budaya Santakasta 


\section{JOGED}

JEPAPLOK:

ISSN: $1858-3989$

$\begin{array}{ll}\text { Nama } & \text { : Rekyan Wimbo } \\ \text { Nareswara } & \text { :Sorogenen II } \\ \text { Alamat } & : \text { 26 tahun } \\ \text { RT02,Kalasan,Sleman,Yogyakarta 55571 } \\ \text { Umur } & : \text { Mahasiswa } \\ \text { Pekerjaan } & \text { : Komposer dan penari } \\ \text { Jabatan } & \end{array}$

$\begin{array}{ll}\text { Nama } & : \text { Lutfi Ahmad P. } \\ \text { Alamat } & : \text { Trenggalek } \\ \text { Umur } & : \text { 22 tahun } \\ \text { Pekerjaan } & : \text { Mahasiswa } \\ \text { Jabatan } & : \text { Penari Barongan }\end{array}$

C. Discografi

Festival 1000 Barongan Nusantara

Jaranan Sentherewe Putra Tunjung Biru Karya tari Jepaplok Bergas pada Ujian Koreografi Mandiri

Video National Dance Competition: Sweet dream. Dance Precisions

D. Webtografi

https://id.wikipedia.org/wiki/Barongan_(mitol ogi)

karya-ilmiah.um.ac.id. Diunggah oleh Dhimas Ageng Sandhimukti, 2014.

http://jokobarongan.blogspot.co.id/2011/05/tar i-barongan.html https://ryan23tulungagung.wordpress.com/201 1/03/22/kesenian- jaranan-budaya-kabupatentulungagung http://tsenicaktri.blogspot.co.id/2013/12/tarijaranan-2.html https://id.scribd.com/doc/124791099/ARTIKE L-JARANAN

Book On Google Play (aplikasi Play Books) 